\title{
Supplementary Materials: Simulating shrubs and their energy and carbon dioxide fluxes in Canada's Low Arctic with the Canadian Land Surface Scheme Including biogeochemical Cycles (CLASSIC)
}

Gesa Meyer $^{1,2}$, Elyn R. Humphreys ${ }^{2}$, Joe R. Melton ${ }^{1}$, Alex J. Cannon ${ }^{1}$, and Peter M. Lafleur ${ }^{3}$

${ }^{1}$ Environment and Climate Change Canada, Climate Research Division, Victoria, BC, Canada

${ }^{2}$ Carleton University, Geography and Environmental Studies, Ottawa, ON, Canada

${ }^{3}$ Trent University, School of Environment, Peterborough, ON, Canada

Correspondence: Gesa Meyer (gesa.meyer@canada.ca)

\section{S1 Supplementary Materials}

The parameters in (Table 2) that were adjusted for shrub and sedge PFTs are used in the following equations. The leaf life span $\left(\tau_{L} ; \mathrm{yr}\right)$ is used to calculate the specific leaf area $\left(\mathrm{SLA} ; \mathrm{m}^{2}(\mathrm{~kg} \mathrm{C})^{-1}\right)$ as

$\mathrm{SLA}=\gamma_{L} \tau_{L}^{-0.5}$

5 with the constant $\gamma_{L}=25 \mathrm{~m}^{2}(\mathrm{~kg} \mathrm{C})^{-1} \mathrm{yr}^{0.5}$. SLA then determines the LAI as

$\mathrm{LAI}=C_{L} \mathrm{SLA}$

CLASSIC includes an age-related mortality $\left(m_{\text {intr }}\right.$; day $\left.{ }^{-1}\right)$ dependent on the maximum age of a PFT $\left(A_{\max }\right.$; yr) with the mortality rate

$m_{\text {intr }}=1-\exp \left(-4.605 / A_{\max }\right)$,

10 so that only $1 \%$ of the vegetation exceeds that PFTs $A_{\max }$, accounting for disturbances like wind throw, insect attacks, hail and others that are not explicitly taken into account in the model (Melton and Arora, 2016).

The root distribution and depth are dynamically simulated in CLASSIC (Arora and Boer, 2003) and have an exponential form, where the cumulative root fraction at depth $z(\mathrm{~m})$ is determined as

$f_{R}(z)=1-\exp (-\iota z)$

15 The depth containing $99 \%$ of the root mass $\left(d_{R} ; \mathrm{m}\right)$ is given by

$d_{R}=\frac{-\ln \left(1-f_{R}\right)}{\iota}=\frac{-\ln (1-0.99)}{\iota}=\frac{4.605}{\iota}$, 
where the exponential root distribution is described by the parameter $\iota$ (dimensionless)

$\iota=\bar{\iota}\left(\overline{C_{R}}\right)^{0.8}$.

The PFT-dependent parameter $\bar{\iota}$ (dimensionless) is given in Table 4 and $\overline{C_{R}}\left(\mathrm{~kg} \mathrm{C} \mathrm{m}^{-2}\right)$ is the average root biomass. If the calculated rooting depth $d_{R}$ exceeds the soil depth or active layer depth, it is set to the soil depth or mean annual maximum active layer depth and $\iota$ is recalculated using Equation S5. The root distribution profile is calculated using the new $\iota$ and then determines the percentage of roots in each soil layer following Equation S4.

Table S1. Soil layer thicknesses, total soil depth and depth of the permeable soil layer used in the simulations.

\begin{tabular}{|c|c|}
\hline Layer & Soil thickness [m] \\
\hline 1 & 0.1 \\
\hline 2 & 0.1 \\
\hline 3 & 0.1 \\
\hline 4 & 0.1 \\
\hline 5 & 0.1 \\
\hline 6 & 0.1 \\
\hline 7 & 0.1 \\
\hline 8 & 0.1 \\
\hline 9 & 0.1 \\
\hline 10 & 0.1 \\
\hline 11 & 0.2 \\
\hline 12 & 0.2 \\
\hline 13 & 0.2 \\
\hline 14 & 0.3 \\
\hline 15 & 0.3 \\
\hline 16 & 0.3 \\
\hline 17 & 0.5 \\
\hline 18 & 0.5 \\
\hline 19 & 0.5 \\
\hline 20 & 1.0 \\
\hline 21 & 5.0 \\
\hline 22 & 10.0 \\
\hline Total soil depth & 20.0 \\
\hline Permeable depth & 5.0 \\
\hline
\end{tabular}




\section{S1.1 Atmospheric forcing data}

The following figures and Table S2 show the atmospheric forcing variables used in the simulations for 2004-2017 as well as the mean values and standard deviation for the full time period and for 2004-2009 and 2010-2017.

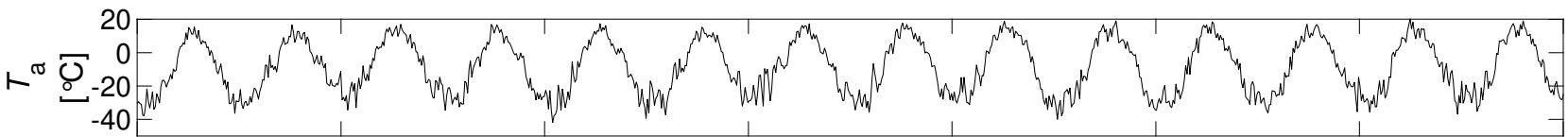

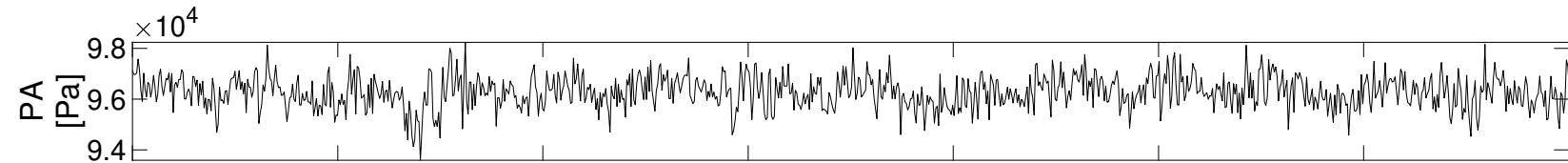
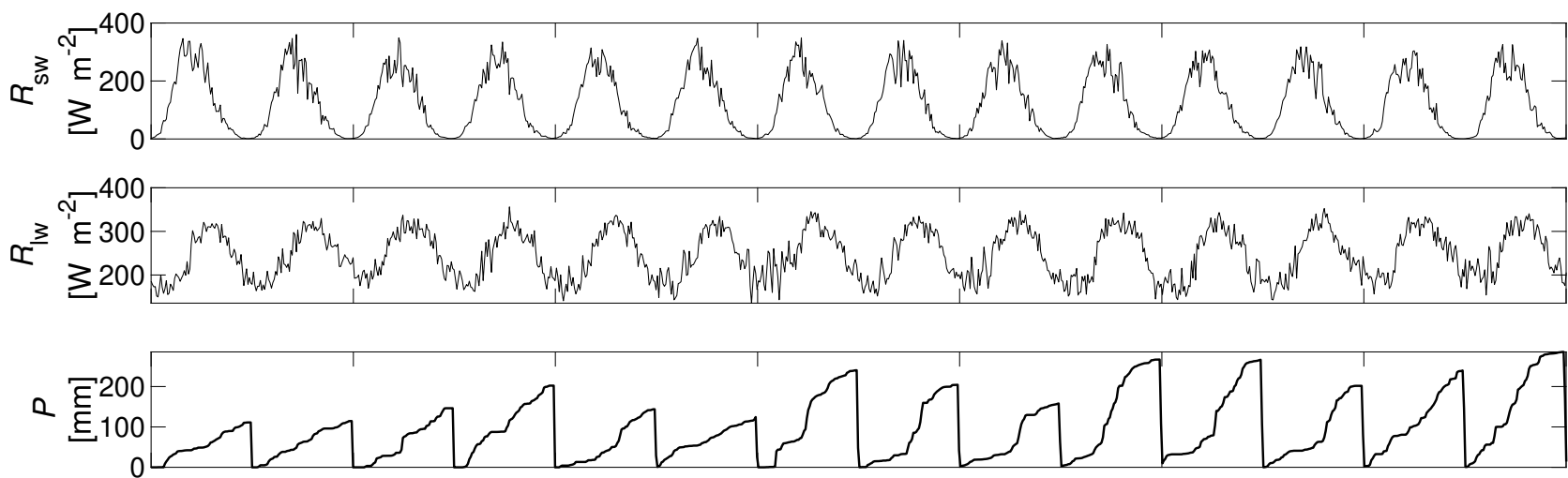

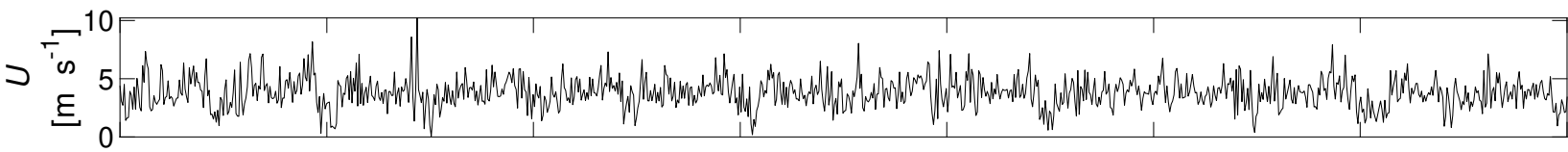

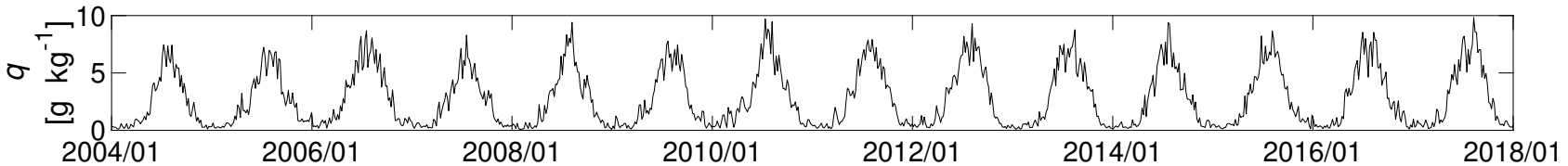

Figure S1. 5-day average atmospheric forcing variables air temperature $\left(T_{\mathrm{a}}\right)$, air pressure (PA), incoming shortwave radiation $\left(R_{\mathrm{sw}}\right)$, incoming longwave radiation $\left(R_{\mathrm{lw}}\right)$, cumulative precipitation $(P)$, wind speed $(U)$ and specific humidity $(q)$ for 2004-2017. 


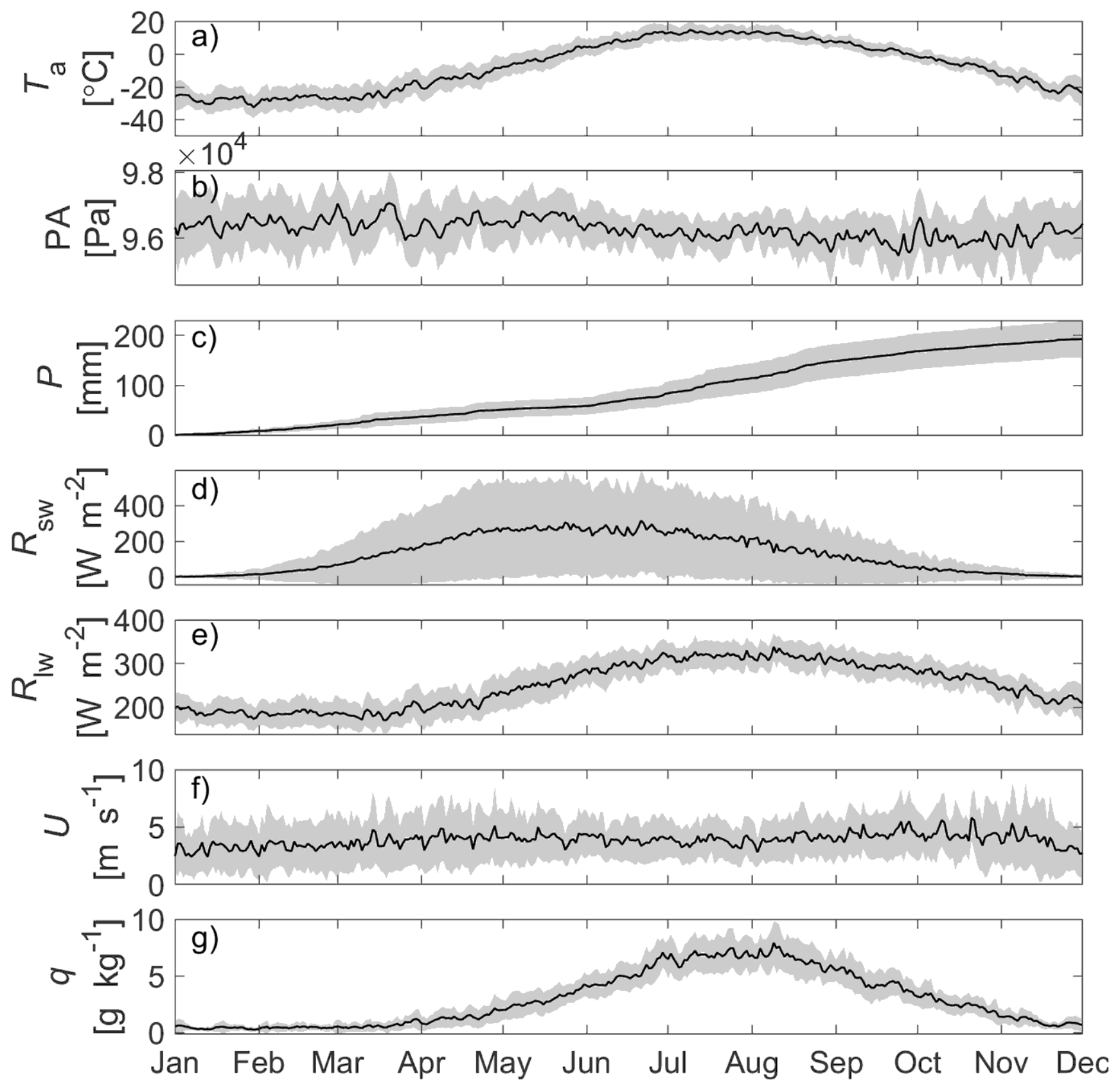

Figure S2. Mean daily air temperature $\left(T_{\mathrm{a}}\right)$, air pressure $(\mathrm{PA})$, precipitation $(P)$, incoming shortwave radiation $\left(R_{\mathrm{sw}}\right)$, incoming longwave radiation $\left(R_{\mathrm{lw}}\right)$, wind speed $(U)$ and specific humidity $(q)$ averaged over 2004-2017. Shaded areas show the standard deviation for $2004-2017$. 
Table S2. Mean \pm SD annual and growing season (GS; May 1 - October 1) air temperature $\left(T_{a}\right)$, total precipitation $(P)$, daily air pressure (PA), incoming shortwave $\left(R_{s w}\right)$ and longwave radiation $\left(R_{l w}\right)$, wind speed $(U)$ and specific humidity $(q)$ averaged over 2004-2009, 20102017 and the whole time period 2004-2017, respectively. Values which are significantly different between the two periods (2004-2009 vs. 2010-2017) are noted by $*(\mathrm{p}<0.05$ using a two-tailed t-test $)$.

\begin{tabular}{c|cc|cc|cc} 
Variable & \multicolumn{2}{|c|}{$\mathbf{2 0 0 4 - 2 0 0 9}$} & \multicolumn{2}{c|}{$\mathbf{2 0 1 0 - 2 0 1 7}$} & \multicolumn{2}{c}{$\mathbf{2 0 0 4 - 2 0 1 7}$} \\
& Annual & GS & Annual & GS & Annual & GS \\
$T_{a}\left[{ }^{\circ} \mathrm{C}\right]$ & $-9.4 \pm 5.3$ & $5.7 \pm 3.9$ & $-8.5 \pm 5.3$ & $7.8 \pm 3.9$ & $-8.8 \pm 5.4$ & $7.0 \pm 4.1$ \\
$P[\mathrm{~mm}]$ & $141 \pm 24^{*}$ & $68 \pm 17^{*}$ & $237 \pm 44^{*}$ & $151 \pm 38^{*}$ & $198 \pm 37$ & $117 \pm 32$ \\
$R_{s w}\left[W m^{-2}\right]$ & $122 \pm 32$ & $203 \pm 57$ & $120 \pm 33$ & $201 \pm 61$ & $121 \pm 33$ & $202 \pm 59$ \\
$R_{l w}\left[W m^{-2}\right]$ & $243 \pm 26$ & $291 \pm 25$ & $248 \pm 29$ & $299 \pm 27$ & $246 \pm 28$ & $296 \pm 26$ \\
$P A[h P a]$ & $962.8 \pm 7.4$ & $962.4 \pm 6.1$ & $962.6 \pm 7.4$ & $961.8 \pm 6.3$ & $962.7 \pm 7.6$ & $962.1 \pm 6.3$ \\
$U\left[\mathrm{~ms}^{-1}\right]$ & $3.9 \pm 1.8$ & $4.0 \pm 1.5$ & $3.8 \pm 1.7$ & $4.0 \pm 1.4$ & $3.8 \pm 1.8$ & $4.0 \pm 1.5$ \\
$q\left[\mathrm{gkg}^{-1}\right]$ & $2.6 \pm 0.8^{*}$ & $4.8 \pm 1.2$ & $2.8 \pm 0.8^{*}$ & $5.4 \pm 1.3$ & $2.7 \pm 0.8$ & $5.1 \pm 1.3$
\end{tabular}




\section{S1.2 Model results}
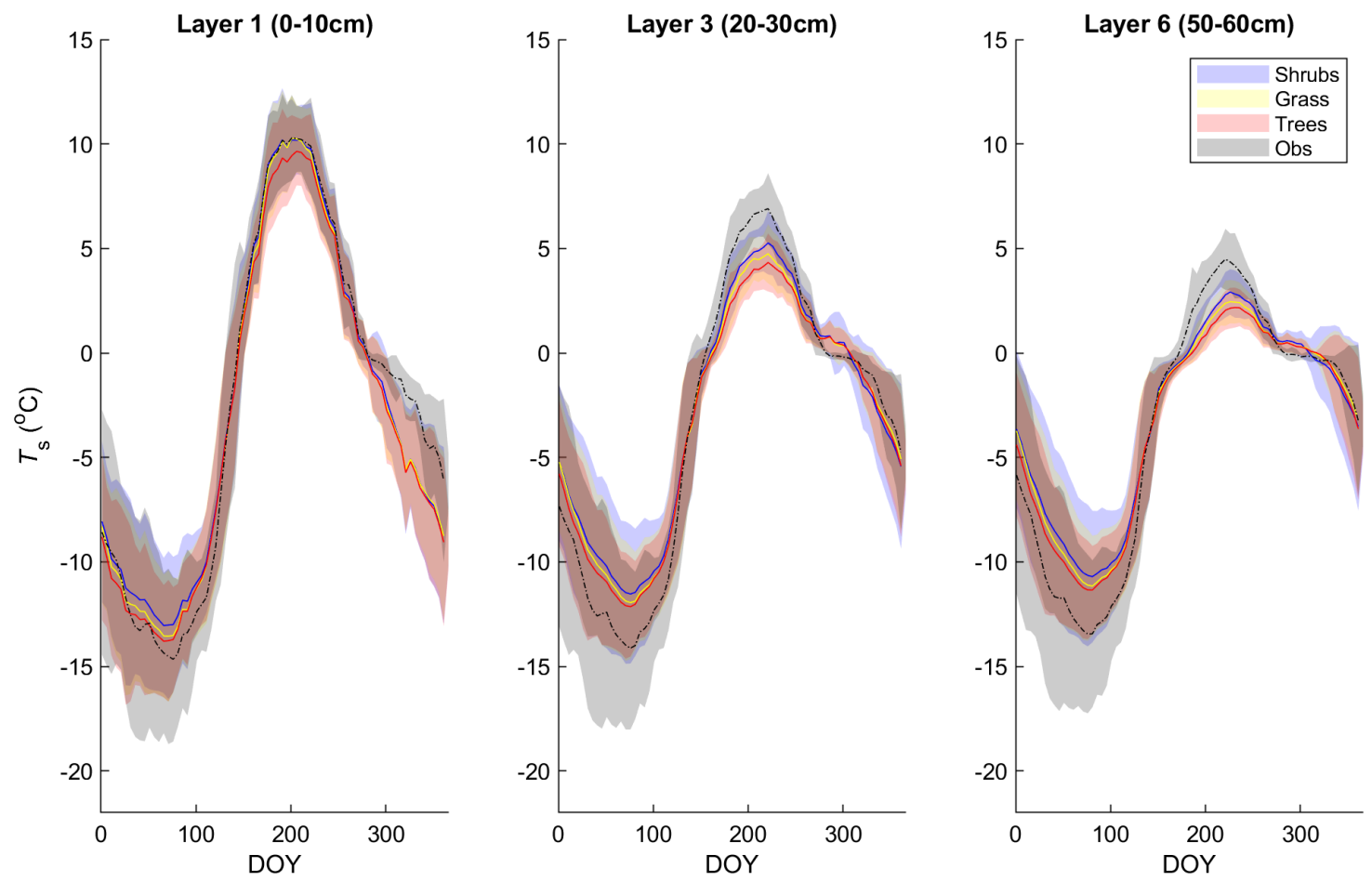

Figure S3. Mean 5-day average soil temperature for layer 1 (0-10 cm depth), 3 (20-30 cm depth) and $6(50-60 \mathrm{~cm}$ depth) of the shrub, grass and tree simulations and measured at 5, 25 and $60 \mathrm{~cm}$ depth, respectively, averaged over 2004-2017. Shaded areas show the standard deviation for 2004-2017. 

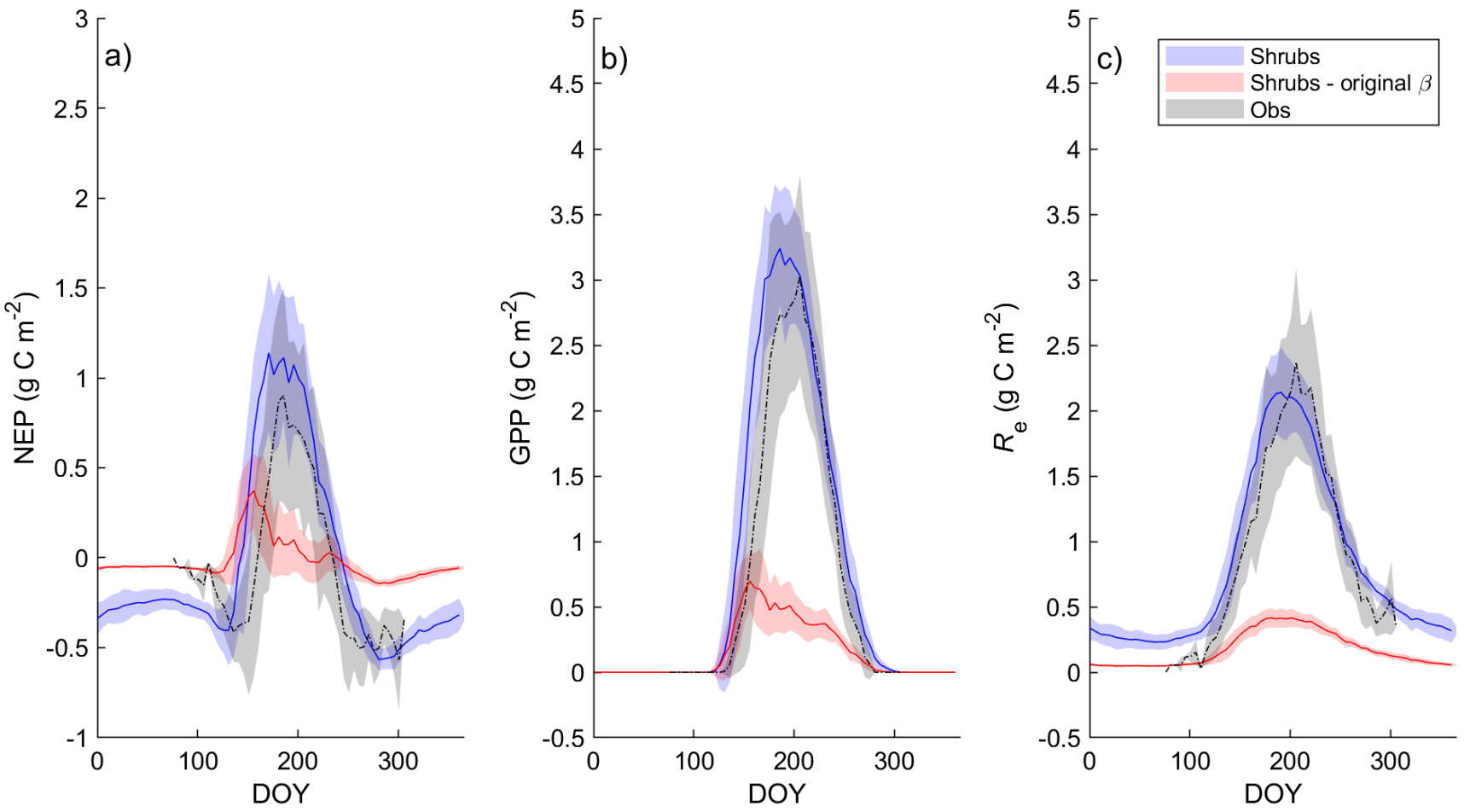

Figure S4. Mean 5-day average a) net ecosystem productivity (NEP), b) gross primary productivity (GPP) and c) ecosystem respiration $\left(R_{\mathrm{e}}\right)$ averaged over 2004-2017 for the shrub simulations using the new (Merlin et al., 2011) and original $\beta$ (Lee and Pielke, 1992) formulation. Shaded areas show the standard deviation for 2004-2017. 
Table S3. Statistics of daily modelled vs. measured values for the shrub, grass and tree simulation.

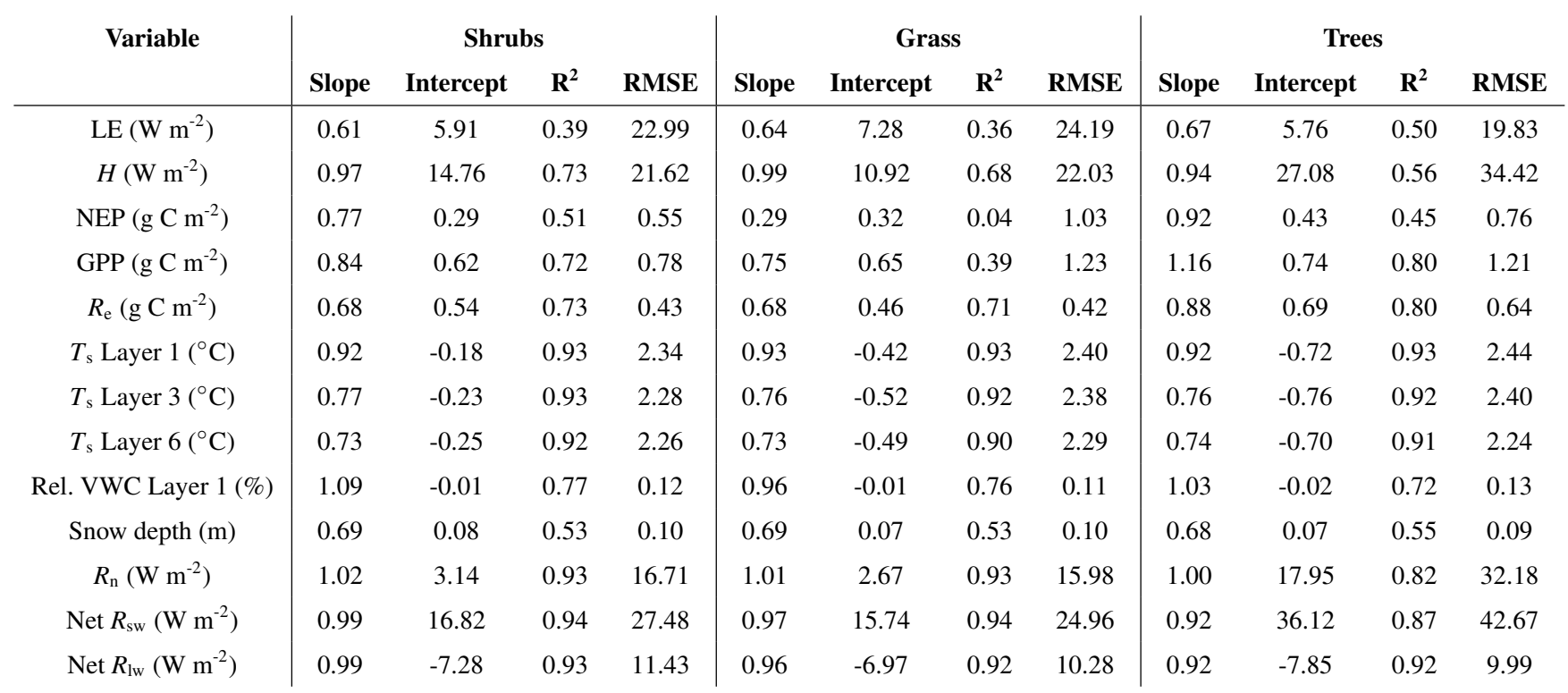




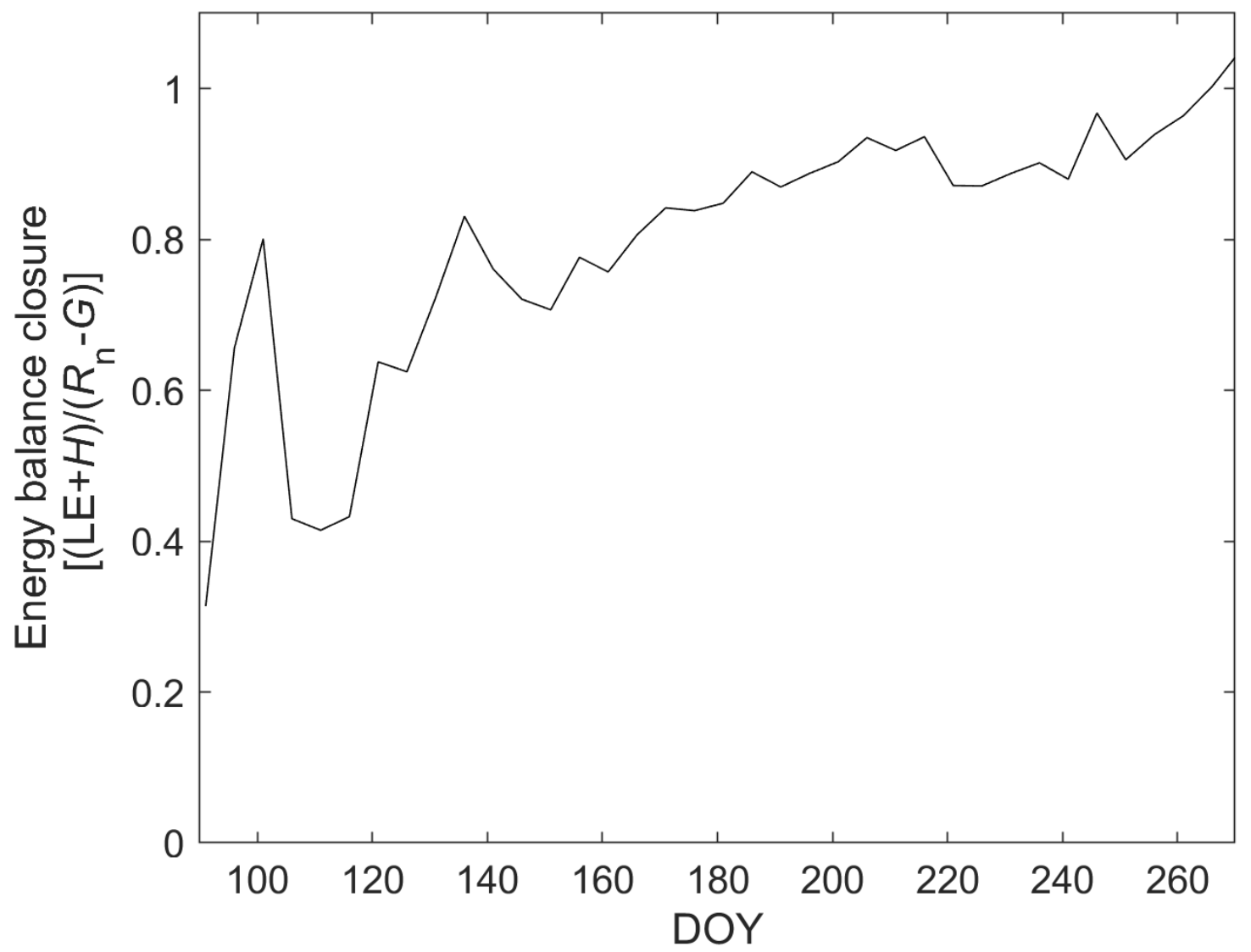

Figure S5. Mean 5-day average energy balance closure at DL1 over 2004-2017 calculated from the EC tower data. 


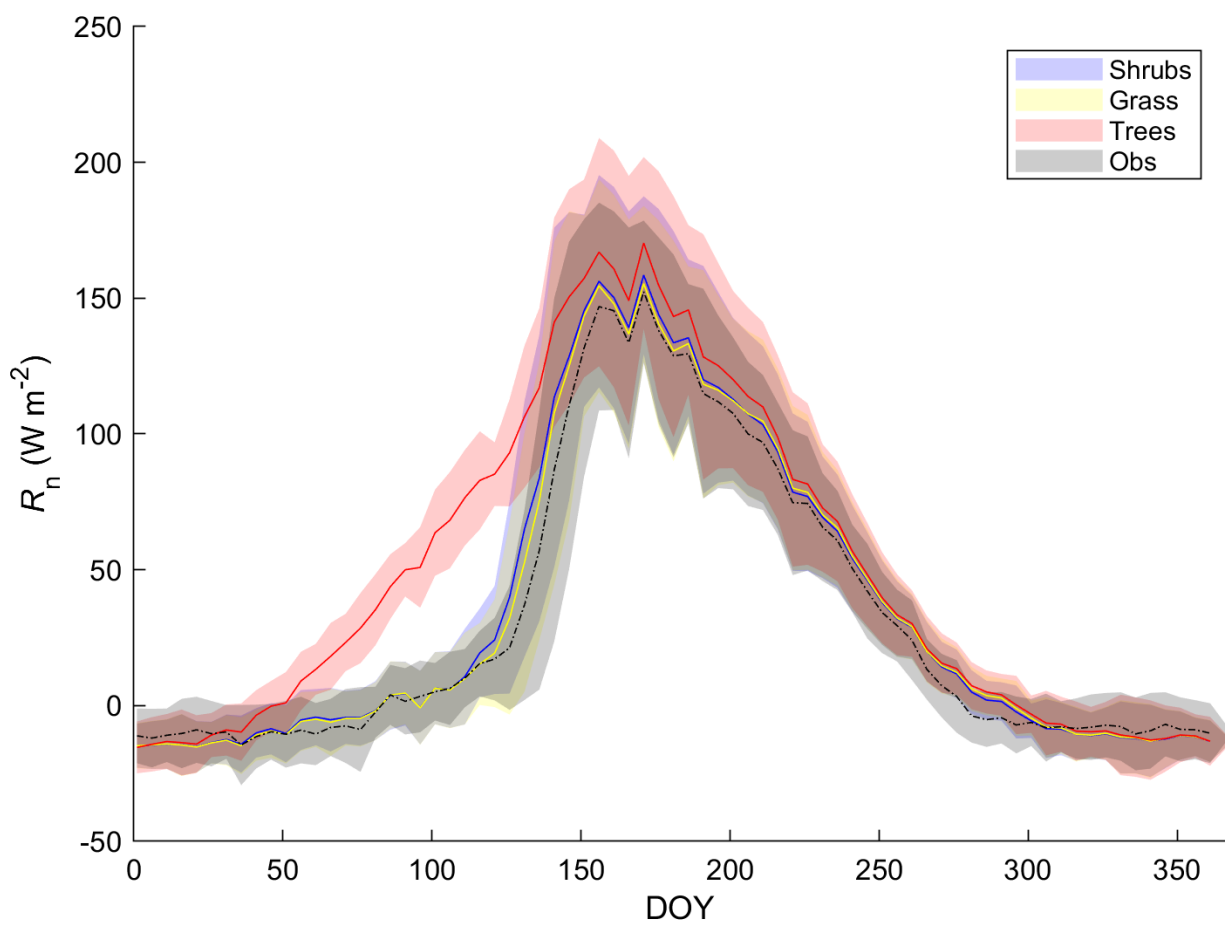

Figure S6. Mean 5-day average net radiation $\left(R_{\mathrm{n}}\right)$ for the shrub, grass and tree simulations as well as measured $R_{\mathrm{n}}$ averaged over $2004-2017$. Shaded areas show the standard deviation for 2004-2017. 

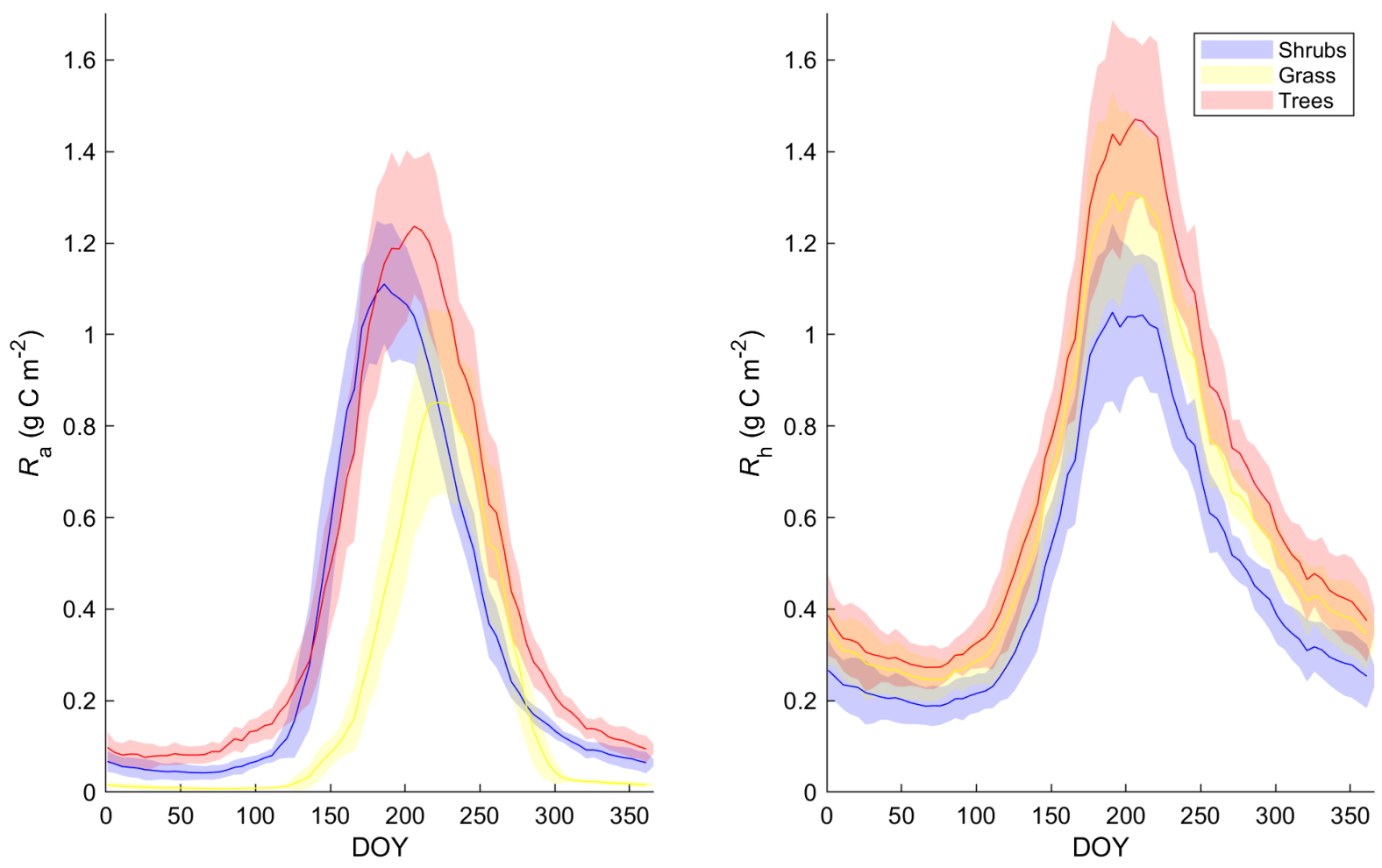

Figure S7. Mean 5-day average autotrophic $\left(R_{\mathrm{a}}\right)$ and heterotrophic respiration $\left(R_{\mathrm{h}}\right)$ for the shrub, grass and tree simulations averaged over 2004-2017. Shaded areas show the standard deviation for 2004-2017. 


\section{References}

Arora, V. K. and Boer, G. J.: A Representation of Variable Root Distribution in Dynamic Vegetation Models I Earth Interactions I American Meteorological Society, Earth Interactions, 7, https://journals.ametsoc.org/view/journals/eint/7/6/1087-3562_2003_007_0001_arovrd_2. 0.co_2.xml, accessed on Wed, August 12, 2020, 2003.

Lee, T. J. and Pielke, R. A.: Estimating the soil surface specific humidity, Journal of Applied Meteorology, 31, 480-484, 1992.

Melton, J. R. and Arora, V. K.: Competition between plant functional types in the Canadian Terrestrial Ecosystem Model (CTEM) v. 2.0, Geoscientific Model Development, 9, 323-361, https://doi.org/10.5194/gmd-9-323-2016, 2016.

Merlin, O., Bitar, A. A., Rivalland, V., Béziat, P., Ceschia, E., and Dedieu, G.: An Analytical Model of Evaporation Efficiency for Unsaturated Soil Surfaces with an Arbitrary Thickness, Journal of Applied Meteorology and Climatology, 50, 457-471, https://doi.org/10.1175/2010JAMC2418.1, 2011. 